\title{
A Study of a Sodium Bicarbonate Cotransporter Functionally Expressed in Xenopuslaevis Oocytes
}

\author{
Tae-Hwan Lee', Sung-Beom Kim¹, Kyung-Pyo Park ${ }^{1}$
}

1. Department of Physiology, School of Dentistry, Seoul National University and Dental Research Institute, Seoul, Korea

\section{Corresponding Author}

\section{Kyung-Pyo Park, DDS, PhD}

Department of Physiology, School of Dentistry, Seoul National University, 28, Yeongeon-dong, Jongnogu, Seoul 110-749, Korea

TEL : +82-2-740-8658 FAX : +82-2-762-5107 E-mail : kppark@snu.ac.kr

\section{Received for publication December 2, 2011; Returned after revision December 19, 2011;}

Accepted for publication December 22, 2011

\section{Acknowledgment}

This work was supported by the National Research Foundation of Korea Grant, through the Oromaxillofacial Dysfunction Research Center for the Elderly (No. 2011-0028231) at Seoul National University in Korea.

\section{- Abstract}

Purpose: $\mathrm{HCO}_{3}^{-}$is the most important ion to buffer the acidity of saliva. The transport of $\mathrm{HCO}_{3}^{-}$is mediated by electrogenic $\mathrm{Na}^{+} / \mathrm{HCO}_{3}{ }^{-}$cotransporter 1 (NBCe1), which expressed in various tissues including salivary glands, kidney and pancreas, etc. This experiment was performed to investigate regulatory site of NBCelinvolved in the $\mathrm{pH}$ regulation using various mutants of $\mathrm{NBCe} 1$.

Materials and Methods: Human parotid gland NBCe1 (hpNBCe1) and mutants by deletion of 1 285 bp and $1 \sim 1,035$ bp were prepared. After microinjection of each cRNA to oocytes of Xenopus laevis, they were incubated for 2 3 days. The function of each protein was tested by electrophysiological method.

Results: When oocytes were exposed to the $\mathrm{HCO}_{3}^{-}$buffered solution, 1 285 bp deleted mutant hpNBCe1 evoked a marked hyperpolarization ranging from $-90 \mathrm{mV}$ to $-160 \mathrm{mV}$ (average: $-134 \mathrm{mV}$; $\mathrm{n}=12$ ) compared to the full length of hpNBCe1. Although 1 1,035 bp deleted mutant hpNBCe1 was also expressed in the plasma membrane, but it did not show any changes of membrane potentials.

Conclusion: Our deletion mutant study demonstrated that 1 285 bp of the NBCe1 is the major domain to determine $\mathrm{HCO}_{3}^{-}$transport ratio.

- Key word : Sodium-Bicarbonate Cotransporter, Intracellular pH regulation, Xenopus laevis oocytes, Deleted mutant hpNBCe1

- J Kor Dent Sci. 2011; 4(2) : 73 - 78

(c) This is an open access article distributed under the terms of the Creative Commons Attribution Non-Commercial License (http:// creativecommons.org/licenses/by-nc/3.0) which permits unrestricted non-commercial use, distribution, and reproduction in any medium, provided the original work is properly cited. 


\section{Introduction}

Sodium/bicarbonate cotransporter (NBC) is a transport protein at the plasma membrane. All subtypes of NBCs transport $\mathrm{HCO}_{3}{ }^{-}$and $\mathrm{Na}^{+}$to the same direction with different ratio, $3: 1$ or $2: 1$, in various tissues and species. In our body, bicarbonate ions alkalize urine and play as an antacid. Thus $\mathrm{HCO}_{3}^{-}$plays the major role in buffering saliva, and $\mathrm{NBC}$ also regulates anion concentration ${ }^{1)}$. By regulation of $\mathrm{HCO}_{3}{ }^{-}$concentration, $\mathrm{NBCs}$ can buffer the acid produced by intraoral bacteria and keep adequate level of $\mathrm{pH}$ for maintaining activity of amylase $\mathrm{e}^{2,3)}$. In parotid glands, the increased concentration of $\mathrm{HCO}_{3}{ }^{-}$by stimulation is sixty-fold higher than that of resting state, showing a maximal buffer capacity ${ }^{4}$. When the flow rate of the saliva

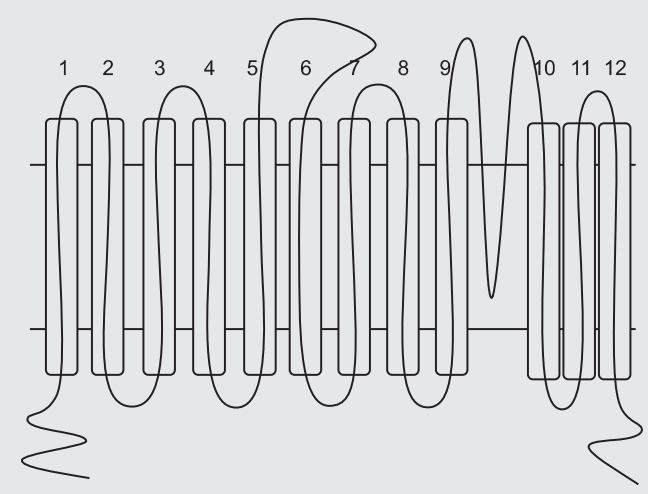

Figure 1. Structure of Sodium/bicarbonate cotransporter (NBC) superfamily.

Tae-Hwan Lee, et al. A Study of a Sodium Bicarbonate Cotransporter Functionally Expressed in Xenopus laevis Oocytes. J Kor Dent Sci 2011. secretion is high, acinar cells secrete more bicarbonate ions, and vice versa. In general, bicarbonate ions are produced by carbonic anhydrase, but the acinar cells of the parotid glands require other transporters which can transport a large amount of $\mathrm{HCO}_{3}{ }^{-}$instantly ${ }^{5}$, and one of the strong candidate is NBC.

NBCs have various subtypes by splicing from one gene. Among the electrogenic NBC1 (NBCe1), the two types of $\mathrm{NBCe}$, $\mathrm{P}$ type and $\mathrm{K}$ type have been reported. It is well known that the P type of NBC expressed in some kind of the exocrine glands, such as pancreas and salivary glands. It also exists in the other tissues like a brain and eyes ${ }^{6,7)}$. On the other hand, the $\mathrm{K}$ type is located in the kidney and regulates the $\mathrm{pH}$ level of the blood. The stoichiometry of $\mathrm{P}$ type and $\mathrm{K}$ type $\mathrm{NBC}$ are $2: 1$ and $3: 1$, respectively (The transport ratios of $\mathrm{HCO}_{3}^{-}: \mathrm{Na}^{+}$). NBC is structurally a member of the SLC4 family with 10 to 14 transmembrane segments. $\mathrm{N}$-terminal and $\mathrm{C}$-terminal are located in the intracellular region and related to the transport of $\mathrm{HCO}_{3}{ }^{-}$ (Fig. 1) ${ }^{4,8,9)}$. Particularly, the function of TM5 domain is inhibited by 4,4'-diisothiocyanatostilbene-2,2'-disulphonic acid (DIDS). There is also N-glycosylation at the $3^{\text {rd }}$ extracellular loop ${ }^{4)}$. According to the previous works on the regulation of the activity of $\mathrm{NBC}$, the PKA dependent phosphorylation site is near the $\mathrm{C}$-terminal of NBC protein and regulates the ratio of transport of $\mathrm{HCO}_{3}{ }^{-}$and $\mathrm{Na}^{+7)}$. Recently, they proved that IRBIT which is produced by $\mathrm{IP}_{3}$ receptor, recognizes specifically and regulates the activity of the $62^{\text {nd }}$ amino acid of the $\mathrm{NBC}^{10}$. They reported that mutations in $\mathrm{N}$ - terminal or $\mathrm{C}$ - terminal makes different NBC currents ${ }^{11)}$.

Although some regulation sites are revealed, the exact regu lation sites remain unknown (Fig. 2). Thus, the aim of our

\begin{tabular}{|c|c|c|c|}
\hline \multicolumn{1}{|c|}{ pNBC } & MEDEAVLDRGASFLK & HVCDEEEVEGHHTIY & IGVHVPKSYRRRRRH \\
\hline KNBC & KRKTGHKEKKEKERI & SENYSDKSDIENADE & SSSSILKPLISPAAE \\
\hline & STENVEGKPSNLGER & GRARSSTFLRVVQPM & FNHSIFTSAVSPAAE \\
\hline & RIRFILGEEDDSPAP & PQLFTELDELLAVDG & QEMEWKETARWIKFE \\
\hline
\end{tabular}

Figure 2. The comparison of N-terminal nucleotide sequences between pNBCe1 and kNBCe1. 
experiments was to find the functional domain of $\mathrm{NBCe} 1$ involved in the $\mathrm{pH}$ regulation. We designed deletion mutants of NBCe1 to determine the regulatory domains. When various deletion of cRNA is expressed in the Xenopus laevis oocytes, the function of each mutant NBCe1 was tested by electrophysiological recordings.

\section{Materials and Methods}

\section{Materials}

Normal HEPES (HBS: $140 \mathrm{mM} \mathrm{NaCl}, 5 \mathrm{mM} \mathrm{KCl}, 1 \mathrm{mM}$ $\mathrm{CaCl}_{2}, 1 \mathrm{mM} \mathrm{MgCl}$, $10 \mathrm{mM}$ glucose, and $10 \mathrm{mM}$ HEPES; $\mathrm{pH}$ 7.4) was prepared. For the $\mathrm{HCO}_{3}{ }^{-} / \mathrm{CO}_{2}$ solution, the 25 $\mathrm{mM} \mathrm{NaCl}$ in the normal HEPES was replaced with $\mathrm{NaHCO}_{3}$ with the same concentration. For the $\mathrm{Na}^{+}$-free $\mathrm{HCO}_{3}{ }^{-} / \mathrm{CO}_{2}$ solution, the $\mathrm{NaCl}$ and $\mathrm{NaHCO}_{3}$ in the normal $\mathrm{HCO}_{3}^{-}$ solution were replaced with NMDG-Cl (N-methyl- Dglucamine) and choline- $\mathrm{HCO}_{3}$, respectively. The DIDS (4,4'-diisothiocyano-2,2'-stillbene-disulfonic acid) was purchased from Sigma (Saint Louis, Missouri, USA).

\section{Methods}

\section{1) Preparation of $c R N A$}

cRNA was prepared using the mMESSAGE mMACHINE ${ }^{\circledR}$ Kit (Ambion). Plasmids that contained hpNBC1 clones/ pBluescript II SK $(+)$ (Stratagene, La Jolla, CA, USA) were linearized, and then cRNA was prepared via in vitro transcription. $1 \mu \mathrm{g}$ of a purified linear template was mixed with the transcription buffer, NTP/CAP, and T7 polymerase, followed by 2 -hour incubation at $37^{\circ} \mathrm{C}$. The template was then removed with TURBO DNase. cRNA was finally obtained via phenol-chloroform extraction and ethanol precipitation. In our experiment, 3 cRNAs - P type hNBC1 (human NBC1), P type hNBC1 deleted at 1 285 $\mathrm{bp}$, and $\mathrm{P}$ type hNBC1 deleted at 1 1,035 bp - were used. In the case of $\mathrm{hNBC} 1$, it was much similar with the P type hNBC except for 1 285 bp.

2) Preparation of Xenopus Laevis Oocytes

Hypothermic anesthesia was administered to the Xenopus laevis, and then oocytes in stages V VI were collected via ovariectomy. They were stored in a modified Barth's solution ( $88 \mathrm{mM} \mathrm{NaCl}, 1 \mathrm{mM} \mathrm{KCl}, 0.33 \mathrm{mM} \mathrm{Ca}\left(\mathrm{NO}_{3}\right)_{2}$, $0.41 \mathrm{mM} \mathrm{CaCl}_{2}, 0.82 \mathrm{mM} \mathrm{MgSO}_{4}, 2.4 \mathrm{mM} \mathrm{NaHCO}_{3}$, and $10 \mathrm{mM}$ Hepes; $\mathrm{pH} 7.5)$ at $18^{\circ} \mathrm{C}$.

3) Expression in Oocytes

The prepared cRNA was injected into the oocyte via microinjection (Nanoliter 2000, manufactured by World Precision Instruments), followed by 2- day incubation in Barth's solution $(100 \mathrm{U} / 100 \mathrm{mg} / \mathrm{ml}$ penicillin/streptomycin, $0.1 \mathrm{mg} / \mathrm{ml}$ kanamycin, $2.5 \mathrm{mM}$ sodium pyruvate, $5 \%$ bovine serum) at $18^{\circ} \mathrm{C}$.

\section{4) Measurement of the Membrane Potential ( Vm)}

The electrode was filled with $3 \mathrm{M} \mathrm{KCl}$ (micro-electrode resistance: 2-4 $\mathrm{M} \Omega$ ), and the membrane potential was measured using a Gene Clamp amplifier. A resting membrane potential of approximately $-60 \mathrm{mV}$ was obtained using normal HEPES solution as the injection solution, followed by sequential treatments with $\mathrm{HCO}_{3}{ }^{-} / \mathrm{CO}_{2}$ solution and $\mathrm{Na}^{+}$-free $\mathrm{HCO}_{3}{ }^{-} / \mathrm{CO}_{2}$ solution for 2 minutes, respectively. Then the membrane potential was recorded by applying the $\mathrm{HCO}_{3}{ }^{-} / \mathrm{CO}_{2}$ solution and the $\mathrm{Na}^{+}$-free $\mathrm{HCO}_{3}{ }^{-} /$ $\mathrm{CO}_{2}$ solution that contained DIDS using the same method used in the aforementioned procedure.

A statistical analysis was conducted using an independentsample T-Test (SPSS). If the test statistic $\mathrm{t}$ was higher than the significance level of 5\% (test value: 2.101 ), the alternatives were accepted.

\section{Results}

The changes of membrane potentials from human parotid P-type hNBC1 (hereinafter, hpNBCe1 full), the deletion mutant hpNBC1 from which the 1st to 285th nucleotides were deleted (hereinafter, hpNBCe1 del 1 285 bp) and the mutant hpNBC1 deleted from the 1st to 1,035 th nucleotides the were deleted (hereinafter, hpNBCe1 del 1 1,035 bp), are presented in Fig. 3.

The membrane potential was hyperpolarized when the $\mathrm{HCO}_{3}{ }^{-} / \mathrm{CO}_{2}$ solution was applied to the hpNBCel full and the hpNBCe1 del 1 285 bp group. Furthermore, the membrane potentials were rapidly depolarized when the $\mathrm{Na}^{+}$-free $\mathrm{HCO}_{3}{ }^{-} / \mathrm{CO}_{2}$ solution was applied to the aforementioned groups. No significant membrane potential change was observed in the hpNBCe1 del 1 1,035 bp group, however. When the normal HEPES was applied to hpNBCe1 full, approximately $-60 \mathrm{mV}$ of membrane potential was observed. Then we changed bath solution containing $\mathrm{HCO}_{3}{ }^{-} / \mathrm{CO}_{2}$ solution for 2 minutes after the stabilization of the membrane potential. Further decrease of membrane potential of $-80 \sim-120 \mathrm{mV}$ (mean: $-100 \mathrm{mV} ; \mathrm{n}=12$ ) was observed. During the plateau of hyperpolarization, exposure to the $\mathrm{Na}^{+}$-free $\mathrm{HCO}_{3}{ }^{-} / \mathrm{CO}_{2}$ then evoked depolarization. While, in the 

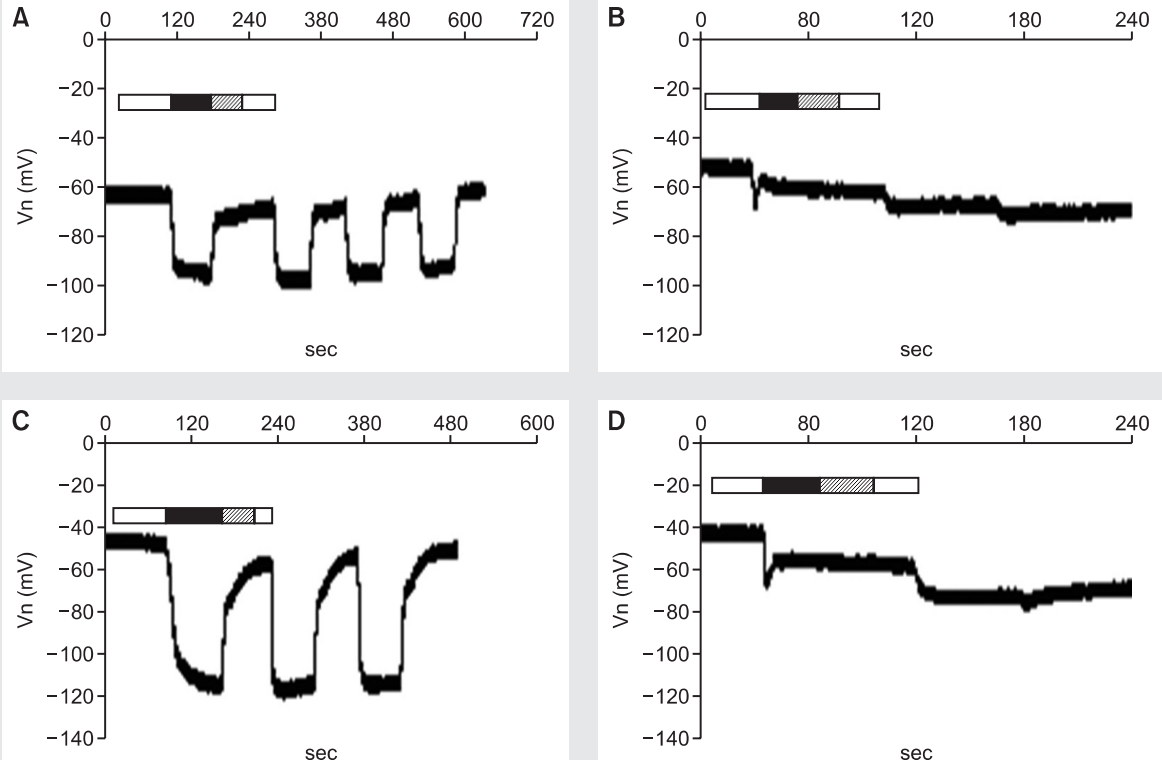

$\sec$

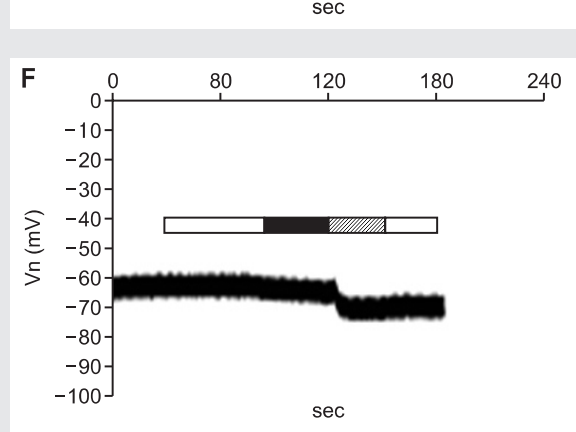

G
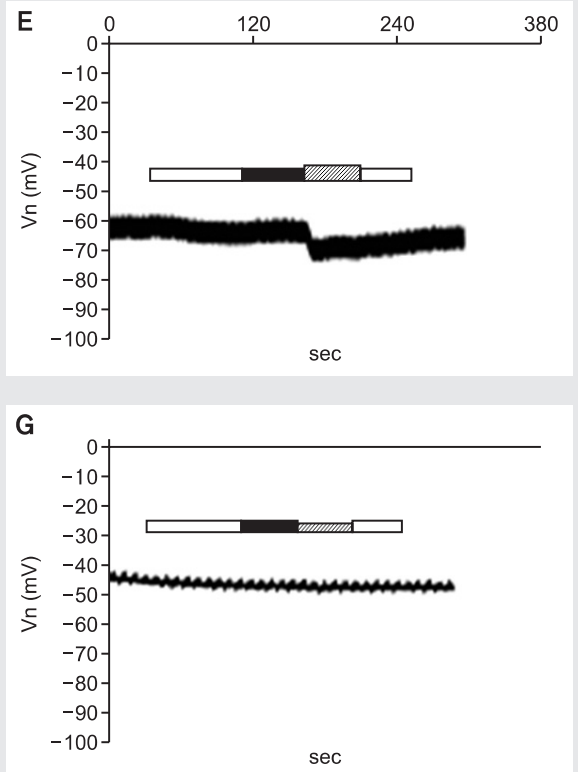

$$
\begin{aligned}
& \square \text { Normal HEPES } \\
& \mathrm{HCO}^{3-} / \mathrm{CO}_{2} \\
& \mathrm{Na}^{-} \text {free } \mathrm{HCO}^{3-} / \mathrm{CO}_{2}
\end{aligned}
$$

Figure 3. Changes of membrane potentials in pNBCe1 expressed in the Xenopus laevis oocytes. (A) Changes of membrane potentials in full hpNBCe1 sequentially induced by normal $\mathrm{HEPES}, \mathrm{HCO}_{3}{ }^{-} / \mathrm{CO}_{2}$ solution and $\mathrm{Na}^{+}$-free $\mathrm{HCO}_{3}{ }^{-} / \mathrm{CO}_{2}$ solution, respectively. (B) Changes of membrane potentials in full hpNBCe1, but pretreated with DIDS (C) Change of membrane potential in hpNBCe1 del 1 285 bp. (D) Changes of membrane potentials in hpNBCe1 del 1 285 bp, but pretreated with DIDS (E) Changes of membrane potentials in hpNBCe1 del 1 1,035 bp. (F) Changes of membrane potentials in hpNBCe1 del $1 \sim 1,035 \mathrm{bp}$, but pretreated with DIDS (G) Changes of membrane potentials in water injected group, which used as a control.

Tae-Hwan Lee, et al. A Study of a Sodium Bicarbonate Cotransporter Functionally Expressed in Xenopus laevis Oocytes. J Kor Dent Sci 2011

hpNBC1 del 1 285 bp group, the degree of the hyperpolarization increased to approximately $-90 \sim-160 \mathrm{mV}$ (mean: $-134 \mathrm{mV} ; \mathrm{n}=12)$ in $\mathrm{HCO}_{3}{ }^{-} / \mathrm{CO}_{2}$ solution. Using the inde- pendent-sample T-test, we obtained $t$ value as 4.215 , which is higher than 2.101 at a significance level of $5 \%$. Thus, the difference between the two groups was considered statis- 
tically significant. Although both the hpNBCe1 full group and the hpNBCe1 del 1 285 bp group showed changes in their membrane potentials, there was a marked difference in the degree of hyperpolarization between two groups. The hpNBCe1 del 1 1,035 bp group was shown to have lost its ability to transport $\mathrm{HCO}_{3}{ }^{-}$. No significant membrane potential change was found in the control group (water injection). DIDS has been known to inhibit changes in the membrane potential as a potent NBC inhibitor. In particular, it has been known to act on the 5th transmembrane domain of NBC. In the hpNBCe1 full group and the hpNBCe1 del 1 285 bp group, DIDS inhibited change of the membrane potentials induced by $\mathrm{HCO}_{3}{ }^{-} / \mathrm{CO}_{2}$ solution and $\mathrm{Na}^{+}$-free $\mathrm{HCO}_{3}{ }^{-} / \mathrm{CO}_{2}$ solution.

Considering the resting membrane potential, the changed values of membrane potentials were approximately $-40 \mathrm{mV}$ for hpNBCe1 full and $-74 \mathrm{mV}$ for hpNBCe1 del 1 285 bp. The ratio of the changes in the two membrane potentials measured was 1.8 , indicating that the change in the membrane potential was similar to the expected ratio value between the hpNBCe1 del 1 285 bp and kNBC1 (Fig. 4). Although The hpNBCe1 del 1 1,035 bp lost its ability to transport $\mathrm{HCO}_{3}^{-}$, its expression was confirmed by confocal images (Fig. 5), indicating that the N-terminal of hpNBC1 involve in the function of hpNBCe1, but not in the targeting of this transport.

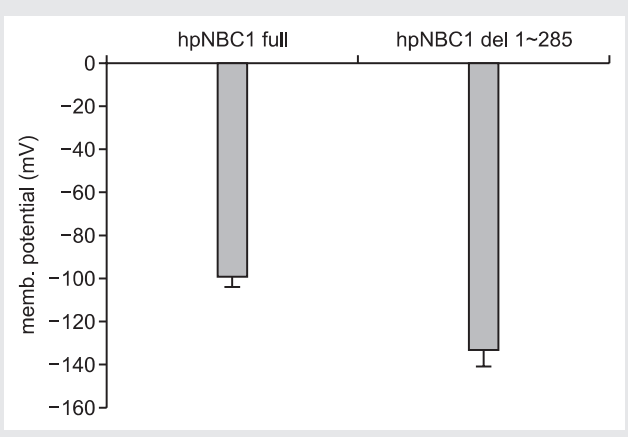

Figure 4. Comparison of the hyperpolarization and the mean value between the hpNBCe1 full group and the hpNBCe1 del 1 285 group.

Tae-Hwan Lee, et al. A Study of a Sodium Bicarbonate Cotransporter Functionally Expressed in Xenopus laevis Oocytes. J Kor Dent Sci 2011.

\section{Discussion}

The stoichiometry $\left(\mathrm{HCO}_{3}{ }^{-}: \mathrm{Na}^{+}\right)$of the P-type NBCe1 and the K-type $\mathrm{NBCe} 1$ has been investigated in various organs and species. The structure of pNBCe1 is identical to that of kNBCe1, except for the 1st to 95th amino acid sequences as pNBC1 and $\mathrm{kNBC} 1$ are expressed via the splicing of the human NBC1(SLC4a4) gene (Fig. 2). The previous studies showed that the stoichiometry of NBC was changed by various cellular signal transmitters. The stoichiometry of $\mathrm{HCO}_{3}{ }^{-}: \mathrm{Na}^{+}$was reported to have been $2: 1$ and $3: 1$ in the $\mathrm{hpNBCe} 1$ and $\mathrm{kNBCe} 1$, respectively ${ }^{4)}$ in the presence of $\mathrm{Ca}^{2+7}$. Changes in the stoichiometry induced by PKA/ cAMP, PKC (protein kinase C), $\mathrm{Ca}^{2+}$, ATP, and $\mathrm{PIP}_{2}$ have been also investigated ${ }^{12-18)}$. In a study in which mice were used, when the N-terminal or C-terminal of NBC was phosphorlylated via PKA/cAMP signal transduction, $\mathrm{HCO}_{3}^{-}$: $\mathrm{Na}^{+}$changed from $3: 1$ to $2: 11^{2,14)}$. In another study, when cellular $\mathrm{Ca}^{2+}$ ions increased, $\mathrm{HCO}_{3}{ }^{-}: \mathrm{Na}^{+}$changed from $2: 1$ to $3: 11^{6}$. Previous study also reported that the stoichiometry was increased by ATP ${ }^{17}$, and that the stoichiometry of $\mathrm{NBC}$ was increased by $\mathrm{PIP}_{2}$, although the regulatory region
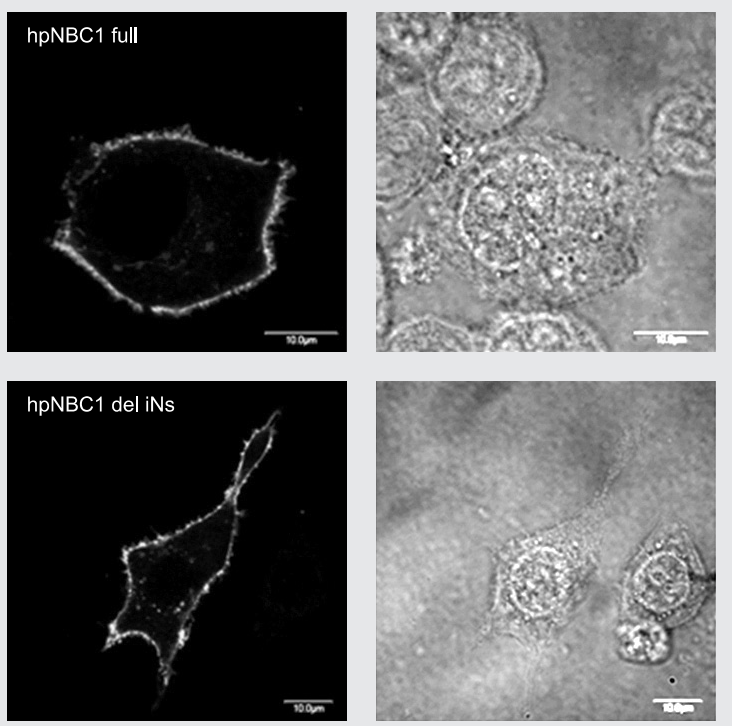

Figure 5. Confocal microscope images for hpNBCe1 full and hpNBCe1 del 1 1,035 bp expressed in HEK cells. Although hpNBCe1 del 1 1,035 bp mutant lost its function, it normally expressed at the membrane.

Tae-Hwan Lee, et al. A Study of a Sodium Bicarbonate Cotransporter Functionally Expressed in Xenopus laevis Oocytes. J Kor Dent Sci 2011 
was not identified ${ }^{18)}$. In addition, the transport of $\mathrm{HCO}_{3}{ }^{-} /$ $\mathrm{Na}^{+}$by NBC was reported to be inhibited under PKC signal transduction or DIDS treatment ${ }^{19)}$.

In our study, the stoichiometry $\left(\mathrm{HCO}_{3}^{-}: \mathrm{Na}^{+}\right)$appeared to change from $2: 1$ to $3: 1$ by hNBC1 in Xenopus laevis oocytes via the removal of different amino acid sequences without the phosphorylation of the N-terminal. Our study also showed that the membrane potential change was approximately 1.8 times in the 1 st- to 285 th-bp deleted pNBC1 group. Theoretically, the change should have been approximately 1.5 times. The value of the membrane potential change was, however, not expressed as an integral, since the whole oocyte membrane changes were measured without considering the volume. Thus, if the in/out of ions per
pNBC is calculated using a patch clamp, it could be possible to conduct a quantitative analysis of ion transport. One possible explanation of the results of this study is that the Thr49 that was located at the N-terminal of pNBC could have changed the stoichiometry of pNBC via its phosphorlyation ${ }^{14)}$. Thus, the transport of $\mathrm{HCO}_{3}{ }^{-}$ions increased as the protein structure of $\mathrm{pNBC} 1$ with the 1 st- to 285 th $\mathrm{bp}$ deleted is similar to that of the phosphorlylated pNBC1. To verify this explanation, a further study is required to identify the structures of $\mathrm{pNBC} 1$ delete from the 1 st to 285 th $\mathrm{bp}$ and the phosphorlylated pNBC1.

Our result might be meaningful in that it is the first study that reported that the stoichiometry changed only with the removal of the different nucleotide sequences.

\section{References}

1. Helm JF, Dodds WJ, Hogan WJ, Soergel KH, Egide MS, Wood CM. Acid neutralizing capacity of human saliva. Gastroenterology. 1982; 83: 69-74.

2. Park K, Hurley PT, Roussa E, Cooper GJ, Smith CP, Thévenod F, Steward MC, Case RM. Expression of a sodium bicarbonate cotransporter in human parotid salivary glands. Arch Oral Biol. 2002; 47: 1-9.

3. Kim YB, Yang BH, Piao ZG, Oh SB, Kim JS, Park K. Expression of $\mathrm{Na}^{+} / \mathrm{HCO}_{3}{ }^{-}$cotransporter and its role in $\mathrm{pH}$ regulation in mouse parotid acinar cells. Biochem Biophys Res Commun. 2003; 304: 593-8.

4. Romero MF, Fulton CM, Boron WF. The SLC4 family of $\mathrm{HCO}_{3}^{-}$ transporters. Pflugers Arch. 2004; 447: 495-509.

5. Jin MH, Koo NY, Jin MH, Hwang SM, Park K. A role of sodium bicarbonate cotransporter (NBC) in $\mathrm{HCO}_{3}{ }^{-}$formation in human salivary gland acinar cells. Int J Oral Biol. 2008; 33: 143-7.

6. Lee HW, Li JC, Koo NY, Piao ZG, Hwang SM, Han JW, Choi HS, Lee JH, Kim JS, Park K. Ca ${ }^{2+}$-activated K ${ }^{+}$Currents of Pancreatic Duct cells in Guinea-pig. Korean J Physiol Pharmacol. 2004; 8: 335-8.

7. Gross E, Kurtz I. Structural determinants and significance of regulation of electrogenic $\mathrm{Na}^{+}-\mathrm{HCO}_{3}{ }^{-}$cotransporter stoichiometry. Am J Physiol Renal Physiol. 2002; 283: F876-87.

8. Koo NY, Li J, Hwang SM, Choi SY, Lee SJ, Oh SB, Kim JS, Lee JH, Park K. Molecular cloning and functional expression of a sodium bicarbonate cotransporter from guinea-pig parotid glands. Biochem Biophys Res Commun. 2006; 342: 1114-22.

9. Choi I, Romero MF, Khandoudi N, Bril A, Boron WF. Cloning and characterization of a human electrogenic $\mathrm{Na}^{+}-\mathrm{HCO}_{3}{ }^{-}$cotransporter isoform (hhNBC). Am J Physiol. 1999; 276: C576-84.

10. Shirakabe K, Priori G, Yamada H, Ando H, Horita S, Fujita T, Fujimoto I, Mizutani A, Seki G, Mikoshiba K. IRBIT, an inositol 1,4,5trisphosphate receptor-binding protein, specifically binds to and activates pancreas-type $\mathrm{Na}^{+} / \mathrm{HCO}_{3}{ }^{-}$cotransporter 1 (pNBC1). Proc Natl Acad Sci USA. 2006; 103: 9542-7.
11. McAlear SD, Liu X, Williams JB, McNicholas-Bevensee CM, Bevensee MO. Electrogenic $\mathrm{Na} / \mathrm{HCO}_{3}$ cotransporter (NBCe1) variants expressed in Xenopus oocytes: functional comparison and roles of the amino and carboxy termini. J Gen Physiol. 2006; 127: 639-58.

12. Gross E, Hawkins K, Pushkin A, Sassani P, Dukkipati R, Abuladze N, Hopfer U, Kurtz I. Phosphorylation of $\mathrm{Ser}^{92}$ in the sodium bicarbonate cotransporter $\mathrm{kNBC} 1$ shifts the $\mathrm{HCO}_{3}^{-}: \mathrm{Na}^{+}$stoichiometry from $3: 1$ to $2: 1$ in murine proximal tubule cells. J Physiol. 2001; 537: 659-65.

13. Gross E, Pushkin A, Abuladze N, Fedotoff O, Kurtz I. Regulation of the sodium bicarbonate cotransporter $\mathrm{kNBC} 1$ function: role of $\mathrm{Asp}{ }^{986} \mathrm{Asp} \mathrm{s}^{98}$ and kNBC1-carbonic anhydrase II binding. J Physiol. 2002; 544: 67985.

14. Gross E, Fedotoff O, Pushkin A, Abuladze N, Newman D, Kurtz I. Phosphorylation-induced modulation of $\mathrm{pNBC} 1$ function: distinct roles for the amino- and carboxy-termini. J Physiol. 2003; 549: 673-82.

15. Romero MF. The electrogenic $\mathrm{Na}^{+} / \mathrm{HCO}_{3}^{-}$cotransporter, NBC. JOP. 2001; 2(4 Suppl): 182-91.

16. Müller-Berger S, Ducoudret O, Diakov A, Frömter E. The renal $\mathrm{Na}-\mathrm{HCO}_{3}{ }^{-}$cotransporter expressed in Xenopus laevis oocytes: change in stoichiometry in response to elevation of cytosolic $\mathrm{Ca}^{2+}$ concentration. Pflugers Arch. 2001; 442: 718-28.

17. Heyer M, Müller-Berger S, Romero MF, Boron WF, Frömter E. Stoichiometry of the rat kidney $\mathrm{Na}^{+}-\mathrm{HCO}_{3}{ }^{-}$cotransporter expressed in Xenopus laevis oocytes. Pflugers Arch. 1999; 438: 322-9.

18. Wu J, McNicholas CM, Bevensee MO. Phosphatidylinositol 4,5bisphosphate (PIP2) stimulates the electrogenic $\mathrm{Na} / \mathrm{HCO}_{3}$ cotransporter NBCe1-A expressed in Xenopus oocytes. Proc Natl Acad Sci USA. 2009; 106: 14150-5.

19. Perry C, Blaine J, Le H, Grichtchenko II. PMA- and ANG II-induced PKC regulation of the renal $\mathrm{Na}^{+}-\mathrm{HCO}_{3}{ }^{-}$cotransporter (hkNBCel). Am J Physiol Renal Physiol. 2006; 290: F417-27. 